\title{
Phase 1 cardiovascular rehabilitation: be aggressive?
}

Vitor Oliveira Carvalho

\section{Background}

It is well known that the most common respiratory complications after cardiac surgery are related to sternotomy, extracorporeal circulation and its inflammatory reaction [1]. Phase 1 cardiovascular rehabilitation is widely indicated to minimize the adverse effects of cardiac surgery, including respiratory function $[2,3]$. However, is there a critical day to physiotherapists?

The study by Moreno et al [4] is very important and adds important information to what we know about respiratory function and physiotherapy after cardiac surgery. This study aimed to assess the pulmonary function in patients after coronary artery bypass graft surgery treated with a physiotherapy protocol. The authors showed that the day 3 after cardiac surgery showed the worst values of forced vital capacity, maximal inspiratory pressure and maximal expiratory pressure in the follow up of 30 days. However, the authors did not show data about the incidence of atelectasis and pulmonary complications along the follow up. The results showed by Moreno et al [4], raised some questions: should physiotherapists be more aggressive in the third day after surgery? If yes, could the aggressive intervention impact in lung complications and survival?

This way, new trials are important to elucidate the best physiotherapy strategy in patients after cardiac surgery. Moreover, to investigate if an aggressive physiotherapy in the worst period of lung function after cardiac surgery decreases the incidence of atelectasis, pulmonary complications and improves patients survival.

Received: 4 October 2011 Accepted: 17 October 2011

Published: 17 October 2011
References

1. Rumsfeld JS, MaWhinney S, McCarthy M Jr, Shroyer AL, VillaNueva CB, $\mathrm{O}$ 'Brein $\mathrm{M}$, et al: Health-related quality of life as a predictor of mortality following coronary artery bypass graft surgery. Participants of the Department of Veterans Affairs Cooperative Study Group on Processes, Structures, and Outcomes of Care in Cardiac Surgery. JAMA 1999, 281:1298-303.

2. Stein R, Maia CP, Silveira AD, Chiappa GR, Myers J, Ribeiro JP: Inspiratory muscle strength as a determinant of functional capacity early after coronary artery bypass graft surgery. Arch Phys Med Rehabil 2009, 90:1685-91.

3. Herbst-Rodrigues MV, Carvalho VO, Auler JOC Jr, Feltrim MIZ: PEEP-ZEEP technique: Cardiorespiratory repercussions in mechanically ventilated patients submitted to a coronary artery bypass graft surgery. $J$ Cardiothorac Surg 2011, 6:108.

4. Moreno AM, Castro RR, Sorares PP, Sant' Anna M, Cravo SL, Nóbrega AC: Longitudinal evaluation the pulmonary function of the pre and postoperative periods in the coronary artery bypass graft surgery of patients treated with a physiotherapy protocol. J Cardiothorac Surg 2011, 6:62-67.

doi:10.1186/1749-8090-6-140

Cite this article as: Carvalho: Phase 1 cardiovascular rehabilitation: be aggressive? Journal of Cardiothoracic Surgery 2011 6:140.

\section{Submit your next manuscript to BioMed Central} and take full advantage of:

- Convenient online submission

- Thorough peer review

- No space constraints or color figure charges

- Immediate publication on acceptance

- Inclusion in PubMed, CAS, Scopus and Google Scholar

- Research which is freely available for redistribution 